\section{O Que Pensam a Franquia Marvel e a História da Ciência sobre a Ciência, 0 Cientista e a Natureza}

\section{Resumo}

Este trabalho discute a representação do cientista, da ciência' e da natureza nas produções cinematográficas Marvel - especificamente os episódios de Homem de Ferro e Vingadores - e em algumas vertentes da História da Ciência. O intuito é o de demonstrar possíveis relações de correspondência e de contraste entre ambas as representações no que concerne à origem, evolução e crise da ciência, à prática da ciência e à ideia de natureza.

Palavras-chave: cientista, natureza, história da ciência, Marvel

\section{Delimitando o objeto deste trabalho}

Dos quadrinhos das décadas de 1940 às franquias cinematográficas, os personagens Marvel têm despertado a atenção de um público, hoje, considerado mundial. Os roteiros carregados de cientificismo e os diversos personagens com suas excepcionais demonstrações de força e domínio sobre os elementos da natureza e da tecnologia, popularizaram temas que há muito são considerados pilares nas ciências em geral e intensamente debatidos na História Social da Ciência que, recentemente, também tem se interessado em discutir representações ficcionais ${ }^{2}$.

A ideia deste trabalho e discutir o que historiadores das ciências têm afirmado, sobre o quanto a vida humana está relacionada à ciência (GRANGER, 1994), sem, no entanto, considerar tal relação de forma determinista. O que se pretende, ao contrário, é apontar algumas formas de se conceber tal relação, isto é, apresentar as

1 Para Schwartzman, não existem consenso sobre o que seja a ciência, mas noções que variam ao longo do tempo e do espaço, não sendo algo simples que se possa definir com facilidade recorrendo a uma boa enciclopédia. Ela é um fenômeno humano e social bastante complexo e variado.

2 GUERRA, Fabio V. A Crónica dos Quadrinhos: Marvel Comics e a História Recente dos EUA (1980-2015). Tese de Doutorado em História Social. História-UFF. Niterói, 2016.
Prof. Me. Carlos

Eduardo Martins.

Mestre em Geografia pela PUC/SP, doutorando em Ensino e História de Ciências da Terra pela UNICAMP. Professor Adjunto na Universidade Cruzeiro do Sul.

E-mail: carlos.martins@ cruzeirodosul.edu.br. 
diversas histórias da ciência e espelhá-las nas representações ficcionais que expressam muito particularmente o seu entendimento sobre a ciência.

Dentre tantas as representações ficcionais admissiveis, a franquia americana Marvel, pelo seu alcance de público, pelas características dos roteiros e particularidade dos personagens, se ajusta melhor ao que se pretende mostrar neste trabalho. O presente texto aponta algumas passagens de três episódios de Homem de Ferro (Iron $\mathrm{Man}^{3}$ ) e quatro episódios de Vingadores (Avengers ${ }^{4}$ ), lançados até o momento, do Universo Cinematográfico Marvel (Marvel Cinematic Universe - MCU5). A análise sobre a cientificidade ${ }^{6}$ nos fragmentos dos episódios selecionados será feita utilizando-se de termos e expressões técnicas dos historiadores da ciência usados como referência para este trabalho.

A delimitação proposta deve-se ao fato de que, diante da diversidade de personagens Marvel Comics surgidos entre a década de 1940 e o presente, os roteiros dos episódios selecionados apontam mais explicitamente para alguns aspectos que se almeja discutir neste texto. Por outro lado, não se pretende dar a quem o lê uma compreensão lógica da continuidade à qual se propõe o Universo

3 Homem de Ferro (2008); Homem de Ferro 2 (2010); Homem de Ferro 3 (2013)

4 Os Vingadores (2012); Vingadores: Era de Ultron (2015); Vingadores: Guerra Infinita (2018) e Vingadores Ultimato (2019)

5 Franquia de mídia produzida pelos Studios Marvel (Walt Disney Studios) a partir das revistas em quadrinhos da Marvel Comics que teve como destaque o editor Stanley Martin Lieber (Stan Lee).

6 A representação de cientificidade nos episódios selecionados, corresponde ao que Granger (1994) entende ser um aspecto de percepção de crise da atual ciência, que tem a ver com a "banalização" dos temas científicos divulgados ao grande público por veículos não científicos. Segundo esse autor, na tentativa de "simplificar" a linguagem científica para a apreensão pelo senso comum, os divulgadores banalizam os temas científicos, muitas vezes distorcendo o que realmente acontece com a ciência e com o cientista. Nesse sentido, o cientista, a ciência e a natureza na perspectiva Marvel podem ser consideradas formas banais de representação do que realmente seriam tais temas.
Cinematográfico Marvel, mas apenas e tão somente demonstrar, no discurso ficcional, o tratamento dado aos termos ciência; cientista e natureza, postos como elementos naturalmente intrínsecos à vida cotidiana, posta como sendo impregnada de pensamento científico, de objetos técnicos e determinada por representações científicas do mundo (GRANGER, 1994).

\section{O cientista, a ciência e a natureza na perspectiva Marvel}

A delimitação proposta, apesar de não abranger toda a sequência de filmes Marvel existente, obedece a uma lógica proposta pelos roteiristas em estabelecer a liderança do Homem de Ferro (Iron Man), o alter ego do físico Antony (Tony) Edward Stark ${ }^{7}$ sobre os Vingadores ${ }^{8}$ (Avengers), a propósito de combater o "mal" que ameaça o Universo.

7 O personagem ficcional Tony Stark é herdeiro de um império industrial armamentista (Stark Industries) formado no período da Guerra Fria. Seu pai foi o principal fornecedor de recursos materiais para as forças aliadas Segunda Guerra Mundial. Precocemente formado em física pelo Massachusetts Institute of Technology (MIT), ao herdar o patrimônio do pai já em um período pós-Guerra Fria, Stark mantém o posto das empresas como principal manancial de armas para o combate ao terrorismo. No desenrolar da trama, em visita ao Afeganistão para uma demonstração de um armamento de elevada letalidade a líderes locais, Stark é vítima de um atentado por um grupo rebelde (The Ten Rings) utilizando uma granada da empresa Stark No cativeiro, ele foi salvo por um físico que implanta um mecanismo eletromagnético que impede que seu coração seja atingido por estilhaços residuais da explosão. A condição para a sua liberdade é construir e disponibilizar para os rebeldes, a mesma arma oferecida aos líderes locais. Percebendo o risco que corria constrói, com a ajuda do seu salvador, uma armadura feita de carcaças de armas o que the permite sair do local com vida. Restabelecido e refletindo sobre as consequências de seus atos, decide interromper a produção de armamentos gerando conflitos na corporação. Descobre que o sócio e amigo de seu pai (Obadiah Stane), já desviava armas para grupos inimigos dos aliados dos EUA, incluindo o The Ten Rings. Derrota-o numa luta em que ambos vestem trajes metálicos desenvolvidos secretamente um do outro, e apresenta à sociedade americana seu alter ego, com a personalidade completamente transformada.

$8 \mathrm{Na}$ versão para o cinema, os Vingadores é um grupo de personagens heroicos reunidos pelo Homem de Ferro para combater o "mal" universal que ameaça a "civilização". 
No roteiro, logo após encerrar a divisão de armamentos da empresa que herdara do pai, Stark é movido por um espírito humanitário extremo e de individualismo exacerbado. Ele crê na tecnologia como (única) forma de acabar com os conflitos universais e alcançar o bem da humanidade. Contrariado pelas forças políticas e econômicas de Estado com as quais mantinha relações comerciais até então, rompe com elas e mergulha em um projeto pessoal de luta contra as "forças" que ameaçam, na sua perspectiva, não só o modo de vida americano, mas também a segurança mundial e até intergaláctica.

Stark cria um centro de pesquisa equipado com um reator privado de abastecimento de energia, acoplado a uma forma de inteligência artificial $^{9}$, que além de interagir com seu criador, gerencia de forma integrada as suas empresas, a armadura do Homem de Ferro e a residência que dispõe de um laboratório particular, no qual são criados e aperfeiçoados os artefatos tecnológicos pessoais, implementados na armadura do Homem de Ferro.

O traje do Homem de Ferro é uma arma de altíssima letalidade com a qual Stark afronta seus inimigos, mas apresenta uma limitação relevante que seria o ponto fraco do herói: o reator em arco portátil instalado no tórax do personagem que, paradoxalmente, o mantém vivo livrando seu coração de ser atingido por estilhaços metálicos resultantes do atentado sofrido no Afeganistão anos antes. No entanto, o artefato estingue aos poucos a vida do personagem pela constante emissão de radiação oriunda do núcleo de paládio, fonte de energia do equipamento. Sabedor de suas limitações e disposto a levar seu projeto a qualquer custo, Stark comporta-se como um déspota esclarecido fora do controle do Estado, mas contando com a colaboração explícita de militares de alta patente bem como de uma agência de

9 J.A.R.V.I.S. (Just A Rather Very Intelligent System). Na versão em quadrinhos, Edwin Jarvis é o mordomo de Tony Stark que se torna um relevante coadjuvante em diversos episódios dando suporte ao Homem de Ferro e mesmo aos outros personagens após a reunião dos Vingadores. segurança internacional ${ }^{10}$, das muitas que, no mundo real, atuam pelo mundo prestando serviços secretos para os EUA.

O comportamento autoritário de Stark é paradoxalmente tolerado por seus compatriotas e odiado por seus inimigos basicamente pelo mesmo motivo: a sua capacidade intelectual e criativa muito acima da média!

A prepotência de Stark se sustenta na condição de equilíbrio internacional que sua armadura proporciona. No roteiro dos três episódios, não foram poucas as tentativas das autoridades do governo americano de assumir o controle sobre a armadura. Em todos os casos, Stark não somente se recusou a ceder seu invento como promoveu ampla campanha pública buscando respaldo popular para manter o controle privado da armadura, ainda que esta fizesse uso do espaço público aéreo e terrestre para promover suas ações bélicas. Como ele mesmo afirma em Homem de Ferro II, para justificar suas ações egocêntricas: "eu privatizei a paz mundial!"

A prática científica de Stark é um dado de bastante destaque nos episódios selecionados. A representação da ciência pela Marvel através do personagem conta com elementos que, de certa, forma sugerem as rotinas experimentalistas que remetem à física quântica, tendo em vista que Stark enquanto físico, manipula de maneira modelas as estruturas moleculares que usa em provento próprio. Entretanto, a física praticada por Stark é extremamente pragmática, individualista, não-parametrizada e anárquica.

As descobertas e invenções de Stark são apresentadas ao público em apresentaçõesespetáculo ("shows") na Stark Expo", na presença

10 Nas versões em português das revistas em quadrinhos: Superintendência Humana de Intervenção, Espionagem, Logística e Dissuasão (SHIELD), foi fundada por Howard Stark, pai de Tony, na década de 1940, para fazer frente a uma agência internacional denominada Hidra que ameaçava o equilíbrio mundial.

11 Evento, originado na versão em quadrinhos, faz referência à Feira Mundial de Nova Iorque 1939/1940, que fazia parte de um amplo programa de recuperação da economia americana após a crise de 1929. As atrações faziam clara referência ideológica ao progresso científico como via do desenvolvimento humano. MARTINS, Rui Cardoso. Exposições Universais; Nova Iorque 1939. URL: https://bit.ly/2KOVOxZl 
de um grande número de expectadores que assistem às demonstrações do poder destruidor da armadura do personagem. Por seu turno, a História da Ciência tem sido igualmente promotora da ideia de progresso em eventos, como uma maneira de estabelecer, de forma linear, evolutiva e dogmática a relação passado-presente-futuro existente na ciência (NISBET, 1985).

Os objetivos de Stark são imediatos e os resultados certos ${ }^{12}$, portanto, a ciência representada pelo sujeito individual empírico (FOUREZ, 1995) de Stark tem, contraditoriamente, um pé no tradicionalismo cartesiano-newtoniano (CAPRA, 2006). Não há teorias para orientar os seus inventos, da mesma forma que os aspectos empíricos não apresentam parâmetro algum. As verificações não têm paralelo e nem são reprodutíveis. Ao contrário, os testes promovidos por Stark frequentemente resultam em disparos acidentais e explosões, se assemelhando bastante ao gênero pastelão do cinema. Fica nítida a intensão do roteirista em representar - cientista como a corporificação da genialidade excêntrica, imoral, irresponsável e quase juvenil através do personagem de Tony Stark.

Tal representação de genialidade é explicitada já no primeiro episódio de Homem de Ferro quando, no cativeiro, Stark constrói o primeiro protótipo da armadura, que seria aperfeiçoada posteriormente, a partir de destroços de armamentos obsoletos remetendo ao provérbio $^{13}$ muito comum usado diante das dificuldades cotidianas reais: se a vida te der limões faça

\section{uma limonada.}

A rotina de trabalho, se é que se pode usar essa expressão, acontece em meio às tarefas como empresário, às relações pessoais e mesmo ao lazer, ou seja, não há o menor sinal de normalidade científica $(K U H N$,

12 Correspondendo ao que foi descrito como prática científica pela História da Ciência do século XVII ao XX (CHRETIEN, 1994).

13 Os provérbios são vistos pelos cientistas modernos e reproduzidos por historiadores da ciência como forma de conhecimento vulgar quando comparado com a ciência experimental (SHAPIN, 2013)
1994) na atividade científica de Stark. Com pouquíssimo esforço de cálculo, manipulação de códigos restritos, deduções matemáticas, simplificações de equações intricadas, Stark reduz a complexidade aparente da natureza e a domina, reduzindo-a às leis naturais simples para, com isso, aperfeiçoar seus inventos de acordo com seus propósitos.

Na cinematografia Marvel, os personagens são humanos superdotados altamente capazes de dominar elementos da natureza por meio da tecnologia. Somam-se a esses humanos de inteligência acima da média, outros que passaram por alguma transformação bioquímica e adquiriram poderes sobre-humanos. Há ainda os seres extraterrestres ou mitológicos que foram condenados a viver eternamente na Terra e, por se solidarizar com os problemas da humanidade, passaram a contribuir com seus poderes para combater ameaças que vez ou outra intentam conquistar a Terra para fins malignos.

O domínio e a consequente manipulação da natureza na ficção, permite a todos esses seres humanos e humanoides, cientistas e magos, terrestres e extraterrestres coexistirem harmoniosamente como Vingadores (Avengers). Há um objetivo consensual entre eles de que todos representam o "bem" devem lutar conta o "mal". E neste caso, o "mal" é, supostamente, a única motivação para a reunião dos Vingadores (Avengers). A maldade personificada nos inimigos a serem combatidos, também se desloca do âmbito humano e terrestre, alcançando o plano extraterrestre e alienígena. O triunfo do mal depende da reunião das "forças" da natureza (Casini, 1987) que se encontram dispersas de forma multidimensional em vários pontos do Universo. E é para evitar tal intento que Tony Stark promove a união dos personagens que constituem os Vingadores para poder combater em várias frentes, já que cada um dos personagens tem poderes específicos.

Na trama ficcional, a reunião das "forças" da natureza sob o domínio de uma mente maligna causaria o desequilíbrio do Universo e promoveria destruição da harmonia nessa dimensão. 
A figura "maligna" do Thanos 14 , personagem que surge em "Vingadores: Era de Ultron" (Avengers: Age of Ultron), como a grande ameaça à humanidade, consegue reunir cinco das seis "forças" da natureza materializadas nas chamadas "joias do infinito". Seis minerais que portam cada um deles uma componente ${ }^{15}$ metafísica que mantém a estabilidade universal. Reunidas, cada uma das joias do infinito tem uma posição específica em uma manopla usada por Thanos na mão esquerda e que supostamente combina as diversas forças de maneira uniforme, absoluta e uniforme.

A reunião e a posse das tais seis joias do infinito é uma alusão ao que, desde a antiguidade, representa a busca pela chamada pedra filosofal. Esse objeto mítico e místico, instigava os alquimistas a compor misturas na tentativa de gerar uma forma sólida poderosa que permitisse ao seu portador realizar qualquer desejo. O recurso ao mito da pedra filosofal já havia sido adotado em Homem de Ferro 2, quando Stark pressionado pelo encurtamento de sua vida devido à contaminação com radiação emitida pelo paládio, resolve inventar ele próprio um elemento químico inexistente na tabele periódica para substituir a fonte contaminante de energia do reator que o mantinha vivo.

Por seu turno, na busca pelo poder absoluto, Thanos, após percorrer diversas galáxias extraindo as cinco joias do infinito, chega à Terra onde, após um confronto decisivo com os Vingadores, obtém a sexta e última joia que é posicionada na manopla, causando uma espécie de hecatombe matando parte da humanidade e diversos Vingadores.

Em Vingadores: Ultimato (Avengers: Endgame), a forma entendida pelos personagens sobreviventes para reverter o problema causado por Thanos no episódio anterior, é

14 Nos originais em quadrinhos, Thanos é um renegado que busca sua redenção pela conquista do poder universal. Tal poder é demonstrado com a morte de metade das formas de vida após adquirir as seis joias do infinito.

15 Espaço (azul); Mente (amarela), Alma (laranja), Realidade (vermelha), Tempo (verde), Poder (roxa). mata-lo, recuperar as pedras do infinito e voltar no tempo para desfazer o "mal" promovido por Thanos. Para isso, inventam uma espécie de máquina para voltar no tempo através de uma dimensão chamada reino quântico. Os personagens se deslocam através de um portal, ou, janela para o passado em ocasiões e locais específicos, recolocando as joias do infinito nos seus lugares originais e revertendo as ações e consequências que efetivamente culminaram no desfecho trágico do episódio anterior. Após uma série de percalços, os Vingadores remanescentes alteram o passado salvando seus pares e o restante da humanidade da morte certa.

Como se viu, há uma série de aspectos de cientificidade representados nas obras ficcionais, muitos deles, problemas não resolvidos nas próprias ciências, tais como a manipulação do tempo e do espaço como se fossem objetos concretos e não categorias do intelecto (SZAMOSI, 1988). Alguns desses aspectos coincidem e outros contrastam com as formas como a ciência é apresentada na História da Ciência.

\section{O cientista, a ciência e a natureza na perspectiva da História da Ciência}

Neste item são expostos alguns aspectos sobre as formas como a História da Ciência trata o cientista, a ciência e a natureza. Os temas tratados estão paradoxalmente ligados aos aspectos discutidos no item anterior. De um lado, trata a historicidade da ciência de modo linear no tempo, inventariando os cientistas considerados geniais e as suas descobertas cientificas quanto à sua correspondência aos princípios científicos mais recentes. De outro lado, os historiadores esforçam-se em desviar-se de temas do cotidiano dos cientistas e do contexto mais geral em que as suas descobertas surgiram.

Na perspectiva tradicional da História da Ciência tudo o que diz respeito ao mundo e 
aos aspectos sociais, econômicos, políticos e culturais passam ao largo das tarefas e mesmo da vida pessoal dos cientistas. Esses são descritos como sujeitos que pensam e agem única e exclusivamente sob a orientação da razão ou como abnegados da vida econômica, dos bens materiais e mesmo isolados das relações interpessoais que se estabelecem no convívio social. A garantia de que sua prática apresente os resultados esperados depende justamente desse isolamento, ou, solitude. A mesma que permite aos artistas compor suas obras primas ou aos profetas ouvirem os mandamentos divinos (SHAPIN, 2013)

Há um certo consenso entre os historiadores da ciência do século $X X^{16}$ de que a origem da ciência ${ }^{77}$ decorre de uma "Revolução Científica" ocorrida na forma de pensar europeia entre os séculos XVI, XVII e XVIII, respectivamente, início, montagem e auge, concomitantemente ao que se convencionou chamar de pensamento moderno ${ }^{18}$ inaugurado pelos filósofos naturais europeus, particularmente, os franceses, os ingleses e os originários da região da Europa que compreende a atual Itália ${ }^{19}$.

Em particular, o pioneirismo da História da Ciência constituiu-se de um consenso para difamar e desacreditar a escolástica medieval ${ }^{20}$ , compreendida pela física aristotélica, pela astronomia ptolomaica e pela medicina galênica, mais prática e/ou técnica, sustentada pela metafísica teológica estruturada por São Tomás de Aquino. Tal conjunto constituía uma

16 Como Alexandre Koyre, por exemplo

17 No século XIX Claude Bernard produziu a seguinte definição: "as ciências partem da observação fiel da realidade. Na sequência dessa observação, tiram-se leis. Estas são então submetidas a verificações experimentais e, desse modo, postas à prova. Estas leis testadas são enfim inseridas em teorias que descrevem a realidade" (FOUREZ, 1995)

18 Os filósofos naturais do Renascimento se autoproclamavam modernos, ou, "novos" para tentar se distanciar dos filósofos escolásticos chamados de tradicionais, ou "velhos" (SHAPIN, 1999)

19 Unificada somente em 1871.

20 O movimento nominalista (passagem do século XIII para o XIV) liderado por Duns Scotus e Guilherme de Occam foi o primeiro manifesto de revolta mais representativo contra a escolástica (DAMPIER, 1986) unidade de abordagem sobre o mundo físico em todas as suas escalas e de grande aceitação até o século XVI (HENRY, 1998 ${ }^{27}$ ).

$\mathrm{O}$ aristotelismo entendia que a forma das coisas era o que determinava a identidade intrinsecamente (não manifesta) admissível na matéria. Na argumentação dos filósofos naturais para negar a escolástica afirmou-se que as observações feitas pelos sentidos, depreciava as descrições do mundo pelo elevado teor de subjetividade (HENRY, 1998). Francis Bacon defendeu a superação das limitações artesanais e da erudição estéril e sem vínculos com a realidade, propondo a articulação de ambas num método ${ }^{22}$ experimental, qualitativo e indutivo. Em paralelo, Galileu Galilei mesmo reconhecendo o valor técnico dos construtores artesãos da Toscana, afirmou a importância da matemática como regra para dar o rigor necessário a uma ciência mecânica (MASON, 1962).

A concepção escolástica foi profundamente abalada com o questionamento Copérnico sobre a física celeste geocêntrica de Ptolomeu, tratada como ortodoxa e apriorística, ela beirava o "ocultismo", como acusou Galileu Galilei (SHAPIN, 1999). Copérnico relativizou a posição da Terra e centralizou o Sol, alterando as bases do sistema astronômico aristotélicoptolomaico. A partir daí a percepção geral passou a ser a de que Copérnico havia "corrigido", ou colocado uma ordem, na matemática astronômica, até então desordenada pelo nível de subjetividade (BURTT, 1983).

Se é que se pode dizer que houve um marco histórico desse contexto, as observações telescópicas de Galileu Galilei sobre as manchas solares, entre outros fenômenos, feitas em princípios do século XVII, desestabilizaram mais ainda as crenças vigentes e hegemônicas da escolástica aristotélica-ptolomáica, pois estas

21 Ao defender a cosmologia copernicana na obra ficcional "Diálogo sobre os Dois Principais Sistemas do Mundo" mediado por Sagredo, Galileu, através do personagem Salviati, crítica impiedosamente o pensamento aristotélico-ptolomaico defendido por Simplício (BURTT, 1983)

22 Fator determinante para o crescimento da ciência moderna (ROSSI,1992) 
atribuíam às irregularidades, admissíveis para Galileu, as forças ocultas impossíveis de serem determinadas. A física celeste era, até então, vista como empiricamente regular e harmônica centrada na Terra (BURTT, 1983).

Crescia entre os matemáticos, a certeza de que era necessário romper com um conhecimento medieval pautado na aparência das coisas, formulando daí uma nova maneira de ver o mundo.

Apesar de todas as formas de resistência que se ergueram a essa tendência, ela começou a atrair cada vez mais defensores (SHAPIN, 1999). A autopromoção foi a estratégia dos filósofos naturais para legitimar o projeto de ciência moderna. De antemão, os filósofos já o consideravam e o divulgavam como universal, garantia de civilidade e de prosperidade para a humanidade (HENRY, 1998). A formulação dos fundamentos de uma teoria para o novo conhecimento coube a John Locke, enquanto a separação e elevação da mente (sujeito) em relação à realidade externa e apropriável objetivamente (objeto), teve a sua formulação creditada a Descartes (RORTY, 1994).

Nessa fase, matemáticos como Galileu, por exemplo, intencionando tornarem-se filósofos naturais de prestigio, visto que a matemática era vista como uma prática técnica, desenvolveram instrumentos para mediar a relação sujeito/ objeto configurando o método experimental. Essa medida garantiria a verdade objetiva da ciência, transformando os fenômenos da realidade física desordenada em fatos ${ }^{23}$ científicos ordenados. Esse passaria a ser apresentado por meio de modelos gerais ou leis a serem aplicados a qualquer situação real (HENRY, 1998).

A objetividade tornou-se o ideal epistemológico para que uma disciplina pudesse superar o estágio pré-científico e se tornar uma ciência propriamente dita, ou seja, fazendo dela um meio capaz de chegar às explicações causais da realidade, sem o emprego do juízo de valor (JAPIASSU, 1975).

23 Construção social e linguística do pensamento da coletividade sobre o fenômeno até alcançar o produto final do pensamento coletivo que é a Gestalt (CONDÉ, 2017)
Os filósofos naturais negaram a escolástica pela sua imprecisão, mas não negam as escrituras sagradas. Eles promoveram a ideia de que a natureza, aparentemente complexa ao homem comum, postulada como inteligível e transparente poderia ser decifrada desde que se compreendesse a linguagem (a matemática) na qual fora escrita (PRIGOGINE e STENGERS, 1984).

Se decifrada, a natureza, como extensão e movimentos regulares (SANTOS, 2008), poderia ser dominada e manipulada para beneficiar o homem. A elaboração de cartas náuticas e de um calendário preciso para orientar as navegações, a cura de doenças, a produção industrial e a bélica ${ }^{24}$ para a proteção das áreas de conquista das metrópoles coloniais, tornaram-se "fins mais nobres" (CHRETIEN, 1994) para aquelas áreas que anteriormente serviam à elaboração de mapas astrais, amenização do sofrimento extremo e um misto de alquimia e magia para aguçar as sensações corporais e a imaginação criativa (CASINI, 1987).

Caberia aos filósofos naturais a tarefa de superar a aparência, promovendo a leitura matematicamente "correta" da natureza, teorizando-a, ou transformando-a em "lei geral" para que pudesse ser usada para fins práticos após testes comprobatórios, chegando à essência. A questão passava daí em diante para a formulação de meios de comprovação que legitimassem a nova ciência (STENGERS, 1989).

Galileu entendia que os movimentos simulados na experimentação artificial, permitiriam deduzir incisivamente os movimentos naturais, vistos a partir daí como suscetíveis de entendimento certo. O que passou a valer foi a ideia de que os movimentos são, das microformas às macroformas, todos mecânicos podendo ser medidos (BURTT, 1983) e, a partir disso, previstos como os de um mecanismo ou uma máquina simples (SHAPIN, 1999). Esse é um momento crucial para o entendimento do que seria a ciência, o cientista e a natureza.

24 No século XVII a Inglaterra já era uma potência militar e comercial. $\bigcirc$ impulso à indústria bélica, dado pelas pesquisas de Galileu em balística, por exemplo, significaram o desaparecimento quase que total das lanças e espadas a partir de 1680 (MERTON 2013) 
Desse momento em diante, os matemáticos descrentes na escolástica aristotélica-ptolomaica, passaram a se ver em uma posição diferente dos matemáticos que permaneciam defendendo aqueles princípios e mantendo-se fieis ao uso da linguagem apenas como técnica, supostamente sem aplicação à realidade. Os descrentes passaram a reivindicar uma nova atribuição para diferenciar-se de vez de seus rivais, se autoafirmando como "filósofos naturais" dedicados, - diferentemente dos matemáticos vistos a partir daí como tradicionalistas - à busca dos padrões formais que regulam o mundo físico, como se este fosse uma máquina (CAPRA, 2006).

Para que a atividade dos filósofos naturais tivesse seu status reconhecido era preciso criar uma nova prática que se distinguisse da anterior. Prática essa, que deveria se notabilizar pelo método, visto como "a" fragilidade na matemática escolástica. Disso decorre o advento da mecânica dos corpos físicos. A mecânica vê o mundo como uma grande máquina preenchida por mecanismos menores e assim sucessivamente até chegar às microformas. O mundo físico visto pelos filósofos naturais era metaforicamente descrito como um relógio ${ }^{25}$, com funcionalidade pré-definida, movimentos precisos, regulares tendo seu funcionamento perpetuado a partir do primeiro impulso dado pelo seu criador, mas manipulável e explicável (SHAPIN, 1999).

O mecanicismo inverteu a lógica aristotélica e a colocou numa condição de ininteligibilidade. Daí por diante, as formas passaram à condição secundária dando apenas contorno à matéria. A filosofia natural determinava a sua posição frente ao aristotelismo apropriando-se e divulgando explicações sobre a natureza, buscando apenas as causas puramente materiais dos fenômenos, explicando o mundo, incluindo a vida em geral a partir de razões mecânicas (SHAPIN, 1999).

25 As metáforas, supostamente combatidas pelos modernos em relação aos medievais, ganharam um status científico para amplificar a objetividade no plano cognitivo do público em geral, convertendo-se na "matéria de fato" da filosofia natural (SHAPIN, 1999).
A História da Ciência chama de revolucionário o conjunto de traços que identificam uma suposta mudança no modo de pensar, na condição social, nas práticas e nas implicações das descobertas mais expressivas dessa fase histórica (HENRY, 1998). Alguns, como Herbert Butterfield, entendem a "revolução" como algo mais significativo até do que o advento do cristianismo, a Reforma Protestante e o Renascimento enquanto forma de conceber a natureza (SHAPIN, 1999).

A expressão "Revolução Científica" ofuscou as formas anteriores de conhecimento ao conceder o status de verdade absoluta à mecânica moderna e deu autoridade inquestionável aos filósofos naturais (HENRY, 1998). Tratava-se de substituir a experiência imediata (observação empírica de uma evidência), vista daí em diante como evidência ilusória (SANTOS, 2008), pelo método experimental (artificial). Nesse, a experiência sensível medieval é rechaçada como algo não-determinado e subjetivo, portanto, desprovido do substrato de uma teoria, de conhecimentos verdadeiro e dos instrumentos que garantem a objetividade da investigação (SHAPIN, 1999).

A História da Ciência empregou a expressão "revolução" para afirmar as transformações ocorridas no século XVI, alegando que uma boa parte das tentativas dos filósofos antigos de formular generalizações, ou, leis gerais, a partir de práticas experimentais limitaram- se ao campo empírico (realidade aparente), implicando efetivamente muito pouco sucesso no progresso da ciência (CHALMERS, 1994). Outros, no entanto, afirmam que, no passado, pode ter havido conhecimento da natureza, mas difundido mais por acidente do que por desígnio (KNELLER, 1980).

As observações a olho nu foram completamente desacreditadas pelos filósofos naturais, quando comparadas à observação astronômica a partir do telescópio de Galileu. A relevância da observação foi preservada, desde que essa fosse realizada de forma padronizada e através de instrumentos. Isso permitiria objetivar satisfatoriamente a observação (CHALMERS, 1994). 
Se, por um lado, a observação a olho nu limitava a apreensão do objeto a partir de um ambiente "poluído" tornando-se, no entendimento dos filósofos, inválida, por outro, os instrumentos foram aceitos enquanto recurso de objetivação da observação, já que avalizariam que o objeto observado seria isolado dos elementos do contexto. A defesa da tese da objetividade residiu no fato de que os procedimentos instrumentais rotineiros, por serem independentes dos sentidos e da percepção, transcenderiam a espaço-temporalidade e as contingências socioeconômicas e culturais. Destarte, a prática experimental consistiria em um procedimento padrão e controlado que poderia ser replicado eternamente como método da ciência (CHALMERS, 1994).

Apesar de todas as premissas e procedimentos, os equipamentos não permitiam ultrapassar os limites de certos resultados. Isso tornou o método experimental e instrumental restrito praticamente desde o princípio. O que exigiu dos filósofos considerar que o método experimental devia ser teórico-dependente. De tal modo, caberia ao sujeito da observação dizer quais objetos deviam ou não serem considerados como "problemas científicos". Essa medida contornaria as dificuldades em definir certas propriedades do real, mantendo a infalibilidade da mecânica e a credibilidade dos filósofos naturais intactas (SHAPIN, 1999).

A teórico-dependência necessária à objetividade da observação reproduziu aquilo que os pensadores antigos já defendiam, que era distinguir e considerar as propriedades ditas primárias, ou seja, "próprias" dos objetos observados, portanto válidas, das propriedades "secundárias" atribuídas ao sujeito da observação, logo falsas (SHAPIN, 1999). O fato de tais objetos válidos, diferentemente dos falsos e "não-problemáticos", apresentarem padrões aceitáveis cientificamente segundo os procedimentos adotados (validações), tornavaos teórico-dependentes e incontestáveis (CHALMERS, 1994).

A História da Ciência surgiu para justificar a ciência moderna. Ao promover o renascimento do pensamento da antiguidade grega para poder "corrigi-lo" (GOLDFARB, 1994) ou trazer soluções para velhos problemas, os filósofos naturais romperam com o conhecimento escolástico aristotélico ensinado nas universidades religiosas e com a tradição mágica medieva ${ }^{26}$.

Em relação à escolástica, a "Revolução Científica" é caracterizada por uma inversão total na abordagem do real. As chamadas "coisas ocultas" na tradição mágica e aristotélica, consideradas intelectualmente insolúveis, forma elevadas à condição de verdade intrínseca, correspondendo então às partículas atômicas do pensamento grego antigo. Já as qualidades manifestas ou evidentes, reconhecíveis empiricamente, passaram a ser vistas como superficiais e decorrentes daquelas, logo, cientificamente inválidas (HENRY, 1998).

As explicações mecanicistas passaram a dedicar cada vez mais atenção ao tratamento micromecânica e microfísico das coisas que o aristotelismo explicava a partir de princípios macroscópicos e experienciais sensórios (SHAPIN, 1999). A diferença estava no método! A ciência, a partir de Descartes considera o pensamento (res cogitans) independente dos objetos (res extensa). O pensamento se apropria apenas dos aspectos matematizáveis ("primários") dos objetos, decompondo-os em partes apropriáveis pelo filósofo e aptas a serem testadas nos instrumentos (BURTT, 1983).

Entre o século XVIII, com a advento das ciências naturais e o XIX, quando tiveram origem as ciências humanas, o positivismo de Comte foi visto como um reforço e tanto para a perspectiva dogmática da ciência. Ele propôs a evolução intelectual humana como uma estrutura linear e progressiva, desde a origem do pensamento mítico, culminando na ciência como o ápice da humanidade com o predomínio da razão, caracterizando uma forma de totalitarismo, ou seja, Comte reforçou, o que Galileu, Descartes e Newton propunham sobre a unificação dos saberes sob ótica da ciência moderna (SANTOS, 2008).

26 Esse recuo ao pensamento grego antigo é justificado pela negação à escolástica, à qual se deseja confrontar e pela defesa da concepção de que o conhecimento antigo foi corrompido ao longo do tempo e que seria preciso retornar às suas bases originais legítimas (SHAPIN, 1999). 
Um aspecto de grande relevância no conteúdo historiográfico da ciência, como já mencionado anteriormente, foi a árdua tarefa de dar credibilidade à ciência moderna, notoriedade à filosofia natural e prestígio aos seus praticantes. Desde a "Revolução Científica", o método experimental era a carta na manga dos filósofos naturais. A publicidade do que a ciência era capaz consistia na promoção de "shows" de demonstrações públicas de experimentos bem-sucedidos que se assemelhavam bastante aos procedimentos da tradição mágica medieval (Henry, 1998). Com a notoriedade dos experimentos, novos praticantes foram aparecendo e os "shows" eram cada vez mais frequentes e executados em novos lugares a cada dia.

A credibilidade pública das teorias e a notoriedade dos filósofos dependiam essencialmente do sucesso dos experimentos. Para tanto, foram criados os mecanismos de validação, considerados muito próximos dos atualmente usados. Para ser considerado válido, o experimento deveria ser controlado, dirigido e disciplinado. Os resultados experimentais, ainda que artificiais, eram declarados como naturalmente válidos e universais.

Essa validação tinha como prerrogativa a crença de que os instrumentos simulavam perfeitamente o comportamento natural do fenômeno, mas de forma controlada. Aos poucos, os experimentos instrumentais e artificiais tornaram-se mais representativos da forma "certa" de se produzirem fatos científicos, que de modo algum poderiam ser observados pelos sentidos, convertendo-se em "norma" científica ${ }^{27}$ (SHAPIN, 1999).

Com o aumento do número de praticantes, da publicidade dos experimentos e dos resultados práticos alcançados, teve início a formação das comunidades de cientistas como grupos socialmente constituídos de acordo com cada atividade. As comunidades científicas passaram a ter o reconhecimento da sociedade, concomitantemente à perda de reconhecimento de outros grupos considerados não científicos. Cada vez mais a comunidade científica passava à condição de domínio absoluto do conhecimento válido e tornava-se a referência para tratar sobre os problemas do mundo (FOUREZ, 1995).

27 Boyle tinha uma preocupação além dos seus contemporâneos na validação dos procedimentos ex-
O aumento do número de praticantes, admiradores e financiadores, além do intercâmbio entre os adeptos do experimentalismo levou também à institucionalização da ciência a partir da fundação, de um lado, das academias de ciência, que tinham vínculos com o poder político e representavam os interesses das elites nacionais e, de outro, das sociedades científicas, como a Royal Society ${ }^{28}$, mais independentes e formadas por indivíduos voluntariosos e vinculados à prática da ciência moderna (HENRY, 1998).

A Royal Society tornou-se o centro da difusão do pensamento científico moderno. Os encontros promoviam os relatos de pesquisas e os experimentos bem-sucedidos da comunidade dos filósofos naturais. Não por acaso, os registros (anais, correspondências e, posteriormente, os periódicos) da Royal Society são considerados o manancial de documentos mais importante para os historiadores da ciência. Sem esquecer que a credibilidade passava também por atender à curiosidade do grande público. Os editores, ou cronistas, da Royal Society publicavam relatos simplificados e resumidos dos documentos originais. Uma espécie de ciência vulgar para o povo (SHAPIN, 1999).

O triunfo da ciência moderna, cada vez mais subdividida em comunidades identificadas por seus discursos diversos e especializados sobre o mundo, mas sob a batuta da mecânica, foi alcançado com a teoria da gravitação universal de Isaac Newton (CAPRA, 2006) um projeto de síntese que faz confessar a natureza de uma só vez a sua verdade oferecida sem mistério: se a maçã cai, tudo cai como ela. Uma só força absoluta, a da gravitação, homogeneíza e alinha

perimentais propõe uma lista de testes validadores, para escapar à condição de individualidade e afastar qualquer traço de subjetividade nos resultados científicos. Newton contrastou Boyle entendendo que deveriam ser adotados apenas os testes considerados mais importantes que produziam as causas verdadeiras para os fenômenos (SHAPIN, 1999).

28 Fundada em 28 de novembro de 1660, em Londres, Inglaterra, após o aumento da frequência de encontros ocorridos desde 1645. Todos os membros da sociedade tinham forte influência religiosa puritana protestante e isso determinou significativamente os propósitos da ciência moderna (MERTON, 2013) 
o movimento astronômico em geral a qualquer movimento relativo na Terra, visto enquanto parte do todo (BOHM, 2008). Estava consolidada a mecânica newtoniana enquanto método universal para a ciência em geral (PRIGOGINE e STENGERS, 1984).

Ao reforçar o grau absoluto (generalista) do movimento físico, já defendido pelos seus predecessores ${ }^{29}$, Newton visou eliminar totalmente os traços de antropomorfismo, ou, de subjetividade existentes nas concepções aristotélicas. O traço de universalidade associado à eficiência e à simplicidade teórica passou a ser visto como parâmetros para o reconhecimento e validação metodológica em todas as ciências, incluindo as humanas, as que conseguiram, em determinados contextos, assimilar o método mecanicista (SHAPIN, 1999).

Sua distinção entre a mecânica e as outras formas de pensar se dá no plano dos objetos do mundo de que trata a primeira, considerados mais fixos ou invariantes e na padronização dos procedimentos reprodutíveis. O conjunto é registrado em uma linguagem específica de altíssima carga simbólica e formal, diferentemente de outros meios de olhar o mundo (o senso comum, por exemplo), considerados mais práticos e superficiais apreendendo apenas sensorialmente os aspectos contingentes da realidade. Assim, enquanto o senso comum apreende apenas as "coisas para nós", a ciência alcança a "coisa em si" (GRANGER, 1994).

Basicamente, o método experimental consiste em procedimentos artificiais, executados em um laboratório, para testar uma hipótese especifica, à luz de uma teoria, com equipamentos específicos, excluindo todas as variáveis, culminando em um produto universalmente replicável ou reprodutível em qualquer situacão (HENRY, 1998). Enquanto as outras formas de conhecimento são consideradas subjetivas, a ciência é tratada como objetiva, ou seja, os

29 Em carta a Hooke, em 1676, Newton proferiu a metáfora "Se enxerguei mais longe que outros homens, foi porque me ergui sobre ombros de gigantes", para se referir ao fato de ter chegado à verdade após as buscas de seus predecessores (BRENNAN, 2003) cientistas observam o mundo físico a partir de um conjunto de aspectos teóricos pré-estabelecidos (válidos) e não com seus próprios olhos (não validos).

A observação (empírica) é, portanto, uma forma de organização da visão sobre o objeto. Observar é uma maneira de pôr ordem o que é observado de acordo com o que interessa ao observador. Elimina-se da observação o que não compreende a forma que se deseja organizar o objeto da pesquisa científica. Assim, uma observação não deixa de ser uma interpretação ou integração do que se observa à representação teórica que temos da realidade (FOUREZ, 1995).

A observação passou a ser o primeiro estágio da teorização sobre o objeto observado. Ao observar um objeto qualquer, o cientista fornece uma teoria do que se vê, utilizando-se as representações teóricas disponíveis, desde observações anteriores. Para isso, no entanto, a observação científica pressupõe uma linguagem convencionada, instrumentalizada. Quando se observa uma célula através de um microscópio já ocorre uma teorização sobre a célula (FOUREZ, 1995).

A objetividade, então, é socialmente construída a partir de linguagens convencionais e não a partir da perspectiva individual do observador. Assim, o objeto é concebível a partir do conjunto de elementos de linguagem científica padrão que permitam comunicá-lo. Não sendo possível convencionar o objeto, não há como objetiva-lo, pois, o caráter objetivo provém diretamente das convenções (FOUREZ, 1995). Se ao invés de personagem ficcional Stark existisse, ele não sobreviveria um só dia como praticante em uma comunidade de cientistas!

Como parte do projeto de autoafirmação da ciência moderna, ao negar a escolástica, os filósofos naturais também negam seus procedimentos. A ideia é eliminar a figura do sujeito da observação, ou, o sujeito individual empírico. Já que ele seria um observador movido por suas paixões e vontades. Suas descrições do mundo, carregadas de subjetividade, teriam um caráter negativo em termos de conhecimento 
certo. Uma das tarefas dos modernos foi a de apagamento, ocultamento ou da obliteração do sujeito individual empírico. Obliterando-o, obter-se-ia a objetividade total em relação ao objeto investigado (FOUREZ, 1995).

No lugar do sujeito individual empírico, os modernos inventaram a figura do sujeito científico. Trata-se do conjunto de atividades estruturantes associadas a uma abordagem científica sobre o mundo e que tem por fim produzir o objeto a ser estudado e convertido em fato científico. Seria um modo socialmente estabelecido de estruturar o mundo, mas sem um indivíduo corporificado.

Essa manobra tem um caráter ideológico bastante acentuado: os traços de cientificidade sobre saberes cujas origens foram suprimidas contrastam com os saberes da vida cotidiana que raramente são chamados de científicos. O apagamento, ocultamento ou a obliteração do sujeito individual empírico, buscam fundar ou legitimar decisões sobre os raciocínios científicos pretensamente neutros e absolutos (FOUREZ, 1995).

Por sua vez, o fato científico é compreendido como algo indiscutível que ninguém coloca em questão, reconhecendo o rigor presumidamente existente no seu estabelecimento. Já as definicões científicas são interpretações das coisas do mundo tornadas objetos científicos padronizados ou conceitos obtidos com o mesmo rigor, das coisas que há no mundo (Fourez, 1995).

A ciência se estabeleceu e evoluiu, a partir do século XVI sendo até o século XIX vista como a autoridade máxima a oferecer a verdadeira interpretação do mundo físico. O problema é que a própria evolução da prática científica contribuiu com os questionamentos que foram feitos sobre ela desde o início do século XX aos dias atuais. Os princípios newtonianos de lei geral da gravitação começaram a ser colocados em dúvida devido a uma série de inovações ocorridas, particularmente, no século XIX ${ }^{30}$.

30 Esse é o período caracterizado pelas independências e dos movimentos abolicionistas generalizados
As pesquisas altamente especializadas em Física, Química, Biologia e Geografia Física, complementadas por diversos inventos técnicos, praticamente ao mesmo tempo, obtiveram sucessos relativos na determinação de diversos processos naturais, até então, inadmissiveis pela mecânica newtoniana. As reações a essas novas formas de conceber a natureza deram início a um movimento de busca por novos paradigmas, o que resultou em um contexto de crise nas bases epistemológicas da ciência moderna (KUHN, 1994).

\section{A crise dos cientistas, da ciência e da natureza}

A noção de crise na ciência moderna começou a ser debatida entre fins do século XIX e início do século XX, chegando aos dias atuais. E foram as transformações ocorridas dentro da física, como já afirmado anteriormente, que causaram o maior impacto na chamada normalidade (KUHN, 1994) da ciência, em especial com as teorias da termodinâmica, da relatividade e da física quântica, às quais já implicavam uma totalidade indivisível do Universo (BOHM, 2008). Essas teorias apresentaram a incerteza, a desordem, a irracionalidade e a proliferação do subjetivismo à comunidade científica (NISBET, 1985). Na ausência da verdade absoluta, os resultados probabilísticos; no lugar da eternidade, a história; em vez de determinismo; a imprevisibilidade; em vez de mecanicismo, a interpenetração, a espontaneidade e a auto-organização; em vez de ordem, desordem; em vez de necessidade, a criatividade e o acidente (MORIN, 2015).

Segundo os críticos das ciências sociais, a ciência moderna, por suas teses eurocêntricas civilizatórias, havia cumprido um papel político-econômico claro, contribuído para a justificativa do colonialismo e imperialismo praticado por estados nacionais europeus e mesmo incentivado os novos estados nacionais

no continente americano. Em contrapartida o capitalismo industrial chegava à sua fase monopolística financeira na Europa. 
a adotar medidas compensatórias coloniais de modo a afirmar a sua condição nacional, acirrando as disputas interimperiais. As consequências desses movimentos em termos sociais haviam sido nefastas para os povos conquistados, ao passo que havia enriquecido sobremaneira a elite europeia ao custo da miséria das colônias americanas, africanas e asiáticas (BRANCO, 1989).

A ciência de base moderna renascentista recebeu um duro golpe a partir da divulgação das teses evolutivas materialistas de Charles Darwin. Importante lembrar que a mecânica newtoniana, herdeira da "Revolução Científica" que se inicia no século XVI, está ancorada na ideia do "primeiro impulso" após a criação, isto é, o movimento iniciado por Deus que coloca toda a máquina do mundo em movimento. Daí por diante, se estabeleceu a regularidade, a imutabilidade e a permanência das coisas criadas.

O princípio darwinista contrariou a regularidade, a imutabilidade e a permanência, instituindo no lugar disso, o processo evolutivo. Segundo Monod (1976, p. 27) (...) "nenhuma outra teoria científica teve consequências filosóficas, ideológicas e políticas tão amplas quanto as da teoria da evolução". Se num primeiro momento o evolucionismo darwinista foi promovido para explicar a vida, logo em seguida ele passou a ser empregado, com certa elasticidade racional, nas mais diversas áreas do conhecimento trazendo novas formas de compreensão aos diversos temas, antes considerados inexplicáveis. Sugere, então, considerar que os evolucionistas se apropriaram da ideia de progresso científico como resultado da evolução biológica (portanto, mental) humana.

O outro duro golpe sofrido pela prática científica moderna, foram as pesquisas atômicas iniciadas entre fins do século XIX e início do XX. A escala atômica passou a exigir cada vez maior integração entre pesquisadores da física, química e biologia, tirando da física a hegemonia que os filósofos naturais tanto defenderam.

Além das mudanças no âmbito do pensamento intelectual, a ciência passou a ser con- frontada também com uma enormidade de aspectos materiais decorrentes da ampliação e diversificação na produção de bens e com a rápida integração dos fatores físicos e culturais, resultantes da ampliação e aceleração dos meios de circulação de pessoas e mercadorias. A velocidade com que as coisas passaram a acontecer, mostraram a fragilidade do método científico em lidar com a diversidade e relatividade do real.

As reações a essas novidades foram bastante diversas tanto na Filosofia quanto na História da Ciência. Em ambos os casos surgiram dois movimentos gerais com nuances interpretativas internas. De um lado, os que defendiam ajustar eventuais falhas, mas manter as bases tradicionais da ciência moderna em uma postura claramente reativa, acusando os críticos de erguerem "obstáculos ao progresso" (Bondi, 1976). De outro, manifestações reformistas das mais variadas tendências, tanto na Filosofia quanto na História da Ciência. Em boa medida, os reformistas passaram a reconhecer, uns mais incisivamente outros nem tanto, o contexto histórico e econômico em que as descobertas foram feitas e as bases ideológicas sob as quais os cientistas atuavam.

Uma terceira via de críticas sobre a prática científica moderna proveio da Sociologia que passou a observar o comportamento social e cultural tanto dos cientistas quanto das comunidades e o meio em que se encontravam, no entendimento das práticas e dos resultados que a ciência produziu. Em suma, a Sociologia da Ciência surgiu das demandas por examinar o fenômeno científico como um fato social. Desse momento em diante, a vida dos cientistas passou a interessar aos sociólogos tanto quanto a dos grupos políticos, econômicos e culturais. A comunidade científica passou a ser considerada um objeto de estudos nos meios acadêmicos das ciências sociais.

Um dado que produziu uma certa perturbação nos meios científicos de modo variável foi o fato de que, a partir desse contexto, tanto a História quanto a Sociologia da Ciência passaram a ser feitas por especialistas oriundos 
da História e da Sociologia e não necessariamente das as áreas científicas que estavam sob julgamento crítico. Esse aspecto também promoveu uma dupla reação nas comunidades científicas criticadas.

Se, de um lado, a persistência de que a história de uma descoberta seria um fato em si mesmo, já que os cientistas são alheios aos propósitos sociais, culturais, políticos e econômicos vigentes e suas descobertas se devem às práticas puras e não aplicadas, de outro, alegava-se que não se podia criticar o trabalho da ciência estando "de fora" dela. O que caberia somente aos próprios cientistas fazerem, se necessária, uma autocrítica à investigação sobre se havia ou não uma crise na prática experimental.

A História da Ciência em geral, foi significativamente abalada pela comunicação do físico soviético Boris Hessen, denominada "As Raízes Socioeconômicas dos Principia de Newton ${ }^{37 "}$, no Segundo Congresso Internacional de História das Ciências, em Londres, em 1931. Tanto na comunicação quanto no artigo publicado nos anais do evento, Hessen fez uma longa exposição dos vínculos entre a mecânica newtoniana e a própria evolução das ciências naturais, enquanto forças produtivas necessárias ao desenvolvimento econômico e militar do capitalismo.

Desde então, diversos outros historiadores da ciência têm buscado associá-la aos interesses econômico-políticos dos estados nacionais. Alguns, como John Bernal ${ }^{32}$, seguiram os passos de Hessen, mas com muito maior profundidade e alcance temático, buscando formular uma História da Ciência universal amplamente orientada por elementos do contexto externo.

As reações dirigidas a Hessen desviaram o foco do problema que ele denunciou. Acusaram- no de querer propagar a ideologia socialista na ciência ocidental, numa clara tentativa de inverter a ordem dos fatos. Hessen estava reproduzindo a própria visão de Marx que afirmou que "para entender a ciência moderna é necessário ver que ela faz parte do capitalismo e tem por objetivo garantir seu crescimento e sua continuidade", e também Lenin que havia

37 The Social and Economic Roots of Newton's Principia. URL https://rtraba.files.wordpress.com/2015/06/ v1_hessen.pdf

32 BERNAL, John D. Ciência na História. Coleção Movimento - 7 volumes. Livros Horizonte, Lisboa, 1969 denunciado os "desvios ideológicos" da ciência no capitalismo (SCHWARTZMAN, 1994).

O contexto descrito por Hessen na sua apresentação, coincide com uma série de transformações ocorridas na Europa decorrentes da transição do feudalismo para o capitalismo e a ascensão da burguesia mercantil. A 'descoberta" do Novo Mundo por meio das navegações oceânicas e consequente instalação do sistema colonial, combinadas às viagens dos naturalistas exploradores e a proliferação dos livros impressos, produziram a ampliação da noção eurocêntrica de mundo. Havia uma necessidade de novas formas de conhecimento que convertessem o grande volume de recursos materiais e humanos disponíveis para o usufruto da sociedade europeia.

Influenciado por esse novo cenário de percepção crítica sobre a ciência, Robert K. Merton (2013), sustentado por Max Weber, identificou entre os fatores externos que influenciaram a origem da ciência moderna no século XVII, tais como a ética puritana protestante que já manifestava desde o fim da Idade Média, além do processo de secularização, que limitou a teologia ao trato do espírito e outorgou à ciência moderna a labuta com a natureza.

No contexto de críticas à ciência, merece destaque o trabalho de Thomas Kuhn (1994) que observou a evolução da ciência a partir de uma análise psicossocial completamente apartado de problemas econômicos, políticos e sociais. Segundo o autor, as ciências funcionam segundo estágios de origem, auge, ou, normalidade e crise de um paradigma, que é a base da investigação da comunidade.

Para Kuhn, a normalidade do paradigma é interrompida pelos debates que se insurgem contra o paradigma vigente quando esse, já não conseguindo contemplar as demandas de resposta do grupo, não resiste e dá lugar, por consenso, a um novo paradigma que restabelece a normalidade nos trabalhos. De forma reducionista, Kuhn limitou a crise da ciência moderna a um mero problema de ciclicidade natural, muito parecido com o que ocorre na 
economia com as ondas longas de Kondratieff (PRIGOGINE e STENGERS, 1984).

Diferentemente dos críticos anteriores, Paul Feyerabend é considerado o maior representante da chamada escola relativista de crítica à ciência (Chalmers, 1994). Na obra "Contra o Método", Feyerabend afirma em tom de denúncia a ausência de idoneidade dos praticantes de ciência quanto ao rigor do método experimental e ao desprezo às outras formas de saber, desde os filósofos renascentistas ${ }^{33}$ até os profissionais de laboratórios dos centros de pesquisas contemporâneos. Na mesmo obra, a comunidade científica é descrita como uma estrutura de especialistas altamente corporativa e competitiva, muito parecida com o que ocorre com as equipes dos departamentos de uma empresa. Além disso, a ausência de rigor nos experimentos de laboratório, recolocaria a magia e a astrologia, nem acima e nem abaixo, mas no mesmo patamar da ciência, em termos de resultados práticos.

A ala talvez mais radical dos críticos da ciência é encabeçada por pensadores como João Maria de Freitas Branco. Na obra "Dialéctica, Ciência e Natureza" (1989), o autor resgata a importância da obra "Dialética da Natureza" (Dialektik der Natur ${ }^{34}$ ) de Friedrich Engels, de 1883. Nessa, Engels demonstra já ter se apropriado dos princípios científicos surgidos nas ciências naturais em meados do século XIX e buscou relacionar tais princípios ao materialismo histórico dialético. Poucas obras foram tão específicas e profundamente analíticas sobre a Dialética da Natureza, como a de Branco.

Para esse autor, a crise que se estabeleceu sobre a ciência somente seria superada com a aplicação dialética da natureza. Talvez por esse motivo, Dialéctica, Ciência e Natureza seja uma obra tão pouco referenciada. O problema

33 Em boa parte dos experimentos, Galileu promovia intervenções para controlar os resultados que desejava, objetivando o método experimental (CHALMERS, 1994).

34 A Dialética da Natureza, de 1883 , seria a obra que Engels dedicaria à crítica à ciência moderna de fato, pois ele já havia iniciado essa abordagem no Anti- é que Engels foi rejeitado até por cientistas marxistas, que o acusaram de perverter os princípios teóricos do "bom" Marx com a tentativa de aplicar a dialética à natureza. É como se a dialética fosse um corpo teórico para um único fim e, pior que isso, como se a contradição fosse apenas antagônica e nunca de interações. Os adversários do marxismo como é o caso de Karl Popper, afirmam que aceitar a contradição (neste caso ele confunde a contradição lógica formal com a contradição dialética) seria equivalente à admissão de inconsistência teórica (BRANCO, 1989).

Engels almejava com a dialética abordar a natureza (física, química e biológica) em movimento, apreender o devir, a contradição existente nos processos, sem isolar os elementos analisados do seu contexto, considerando todas as forças que atuam sobre ele, isto é, usar a dialética como recurso anti-idealista, anti- mecanicista e crítico a esses em relação ao não-concebimento do mundo como processo. Branco alertou para o cuidado com os dogmas. Segundo ele, a contradição não deve ser um modelo geral ou uma generalização que se imponha ao real objetivo. Deve-se identifica-la e especificada no mundo real, isto é, deve-se analisar como as contradições ocorrem caso a caso (BRANCO, 1989).

A proposta de Engels busca a dimensão não- definitiva de verdade, não querendo afirmar com isso que haja ausência de conhecimento. $O$ que importa para ele é a abolição da definição entendida como verdade acabada, eterna e absoluta e a adoção da verdade provisória. Para Engels, o universo não é um caos, mas o cosmos que tem uma ordem inteligivel, mas que não é invariante. Assim o modelo de investigacão válido deve ser móvel e compatível com a dinâmica dos processos. Engels não propõe a criação de uma ciência nova, mas visa rearranjar os currículos e reagrupar os métodos para

Duhring, de 1878, quando atribui, por exemplo, um valor relativo à evolução e aos alcances da ciência, ressaltando que todo o progresso nos modos de análise teria sido destacado da grande concatenação do universo (ENGELS, 2015) 
que as especialidades científicas, nas suas particularidades, dialoguem umas com as outras na forma de uma inédita transdisciplinaridade (BRANCO, 1989).

Uma outra vertente da crítica à ciência chama a atenção para a relação com a sociedade patriarcal em que vivemos. A ciência é uma atividade masculina, feita por homens para servir aos interesses patriarcais da sociedade ocidental (CHASSOT, 2003). Nessa divisão sexista persistente desde o renascimento na ciência, a justificativa para a ausência quase que total de mulheres na atividade, se dá em função das crenças de que o pensamento feminino sendo movido pelos sentimentos difere do pensamento masculino, voltado à razão, além da ausência naquele da capacidade de abstração (SHAPIN, 2013).

Em meio aos debates sobre as diversas fragilidades levantadas sobre a prática científica, surgem as tentativas de contornar os problemas nascidos das críticas. Para uns, como é o caso de Wittgenstein (2008), o problema do método científico para abordar corretamente a realidade estava ligado à linguagem, mais especificamente à sintaxe do discurso. Para outros, como Popper (2016), a questão seria resolvida a partir da remodelação da validação e da confiabilidade dos testes, adotando-se a amenização dos critérios de falseamento sobre os procedimentos. Mais recentemente, figuras como Chalmers (1994) intentam salvar a ciência afirmando a necessidade de resguardar seu propósito de gerar benefícios à humanidade ${ }^{35}$, mas defendem o abandono as generalizações.

Em outros casos, a perspectiva de crise gerou defesas da necessidade de vincular a ciência a outros saberes com os quais ela vinha se confrontando e, em alguns casos, desprezando como formas de conhecimento. Edgar Morin (2015) ressalta a necessidade de incorporar as novidades do mundo ao pensamento científico,

35 Na obra Nova Atlantida, Bacon fantasia um lugar movido pela razão das mentes mais brilhantes da sociedade, mobilizadas e agrupadas na "Casa de Salomão" para coletivamente, criar as bases para o bem-estar da humanidade. invertendo o método disjunto e simplificador da ciência moderna, isto é, em vez de simplificar/ ordenar as coisas do mundo a partir da aparente complexidade, deve-se complexificá-las/ desordena-las a partir da sua aparente simplicidade/ordem.

Como o treinamento dos cientistas ocorreu invariavelmente sobre bases positivistas fragmentárias, Morin sugere que a superação da crise seja uma tarefa coletiva ${ }^{36}$ na qual cada especialista contribua com a sua parte, sem que haja sobreposição de nenhuma área sobre a outra, o que ele chamou de religação necessária dos saberes. A abordagem sobre a natureza também deveria ser outra. Diferentemente do que os cientistas tradicionais, a perspectiva organicidade mecânica e estática que considera a natureza um mecanismo estático, deveria dar lugar a uma abordagem orgânica viva, dinâmica e mutável.

A esse mesmo grupo de críticos que julgam haver necessidade de integração da ciência com outros saberes, Fritjof Capra (2006), também aposta na renovação da prática a partir da adoção de conhecimentos anteriormente confrontados ou simplesmente ignorados pelos modernos. Em particular, as fontes orientais do conhecimento, onde ainda, segundo ele, se preserva a perspectiva da totalidade do mundo.

Para Capra, a ciência moderna que impregna e dificulta as respostas da prática contemporânea aos problemas do mundo atual, deveria incorporar princípios da filosofia oriental, buscando assim um equilíbrio nas suas ações. Capra afirma, sem necessariamente aprofundar as causas, que a trajetória do conhecimento ocidental se desviou para um caminho pragmático à economia. Esse traço de pragmatismo se combinado à harmonia do pensamento oriental poderia recolocar a ciência nos trilhos do bem-estar humano.

Tanto Morin quanto Capra afirmam haver uma crise ecológica da qual a ciência é, em grande medida, responsável tendo em vista que

36 Não assume parafrasear Engels, mas emprega a perspectiva transdisciplinar 
a atividade científica esteve sempre voltada à subordinação e à exploração da natureza. Ambos concordam que a reorientação no traçado da prática científica evitaria um futuro marcado por pessimismo e alarmismo quanto às condições de vida na Terra. Some-se às visões desses autores, as teses de Leonardo Boff que defende um novo ethos para interromper o ciclo de crise da ciência. Para Boff, o "cuidado" deve-se somar ao "trabalho", como forma de superação da relação sujeito-objeto de domínio do homem pela natureza, alternado para uma relação sujeito-sujeito, ou seja, de equilíbrio entre homem e natureza.

Uma das críticas mais contundentes partiu de Gaston Bachelard, quanto à persistência em negar os fatos de que o método científico estaria esgotado. Ele assevera que tal comportamento pode estar associado aos dividendos políticos e econômicos que se extraem da ciência, ou seja, a produção de bens materiais necessitaria seguir seu curso, mantendo o utilitarismo ao qual os serviços da ciência se voltaram, constituindo-se "obstáculos epistemológicos" (BACHELARD, 2016). Isso teria dificultado o progresso da ciência teórica, pois, os cientistas se ocupam com a aplicação do saber consagrado e não na recriação desse saber.

Santos (2008) foi mais longe na identificação da condição sociológica que envolve os cientistas. Para ele, os cientistas são objetos de proletarização dentro dos laboratórios e centros de pesquisas, portanto, sociologicamente, a comunidade científica deve ser vista como força de trabalho e/ou parte das forças produtivas do capitalismo. Sobre esse mesmo ponto de vista, Chretien (1994) afirma que os cientistas são, de um lado, mão de obra altamente especializadas no âmbito dessas mesmas forças produtivas e Morin (2015) sugere que, sobretudo, os cientistas são completos ignorantes em relação à sua condição social.

Como se pôde notar, a crise que se estabeleceu contemporaneamente sobre a ciência pode ser caracterizada nos mais diversos matizes pelas próprias insuficiências, equívocos, ideologias, espírito corporativo, pragmatismo econômico-político e mesmo por alienação.

Na História da Ciência, há uma longa e persistente tradição de abordagem sobre os grandes feitos dos gênios que aparecem de tempos em tempos e que revolucionam a forma como o mundo é visto. Esse tradicionalismo está ancorado em atribuir o invento ao inventor nas ocasiões em que estes são pegos subitamente por "insigths" de brilhantismo esporádico. Esse ponto de vista apresenta os cientistas como os únicos humanos dotados da competência de "ler" abstratamente a natureza para tirar dela o que a humanidade deseja para o seu conforto.

Na tradição do pensamento historiográfico da ciência, os cientistas têm sido reverenciados e prestigiados política e socialmente. Todo o crédito se deveu a um discurso estabelecido sobre um substrato metodológico, baseado na razão a partir da decomposição dos objetos reais e redução às suas extensões matematizáveis, culminando em generalizações com pouca eficácia de aplicabilidade no cotidiano da maioria da população da Terra (PRIGOGINE e STENGERS, 1984).

Na perspectiva crítica, a comunidade científica, apesar de designada como um sujeito indeterminado, deve ser compreendida como uma estrutura horizontal sob pena de se ocultar divergências profundas de interesse. Uma estrutura social hierarquizada com uma divisão do trabalho, na qual o prestígio, a notoriedade e a credibilidade da ciência e do cientista envolve prestígio, dinheiro e status social.

Tal cenário, implica diretamente na canalização de verbas (em geral públicas) para certos projetos em detrimento de outros que, ainda que sejam socioeconomicamente relevantes, estejam sob a orientação de cientistas com menos reconhecimento na comunidade (SHAPIN, 1999). A divisão do trabalho ocorre tanto entre os cientistas da comunidade quanto entre os centros de pesquisas nacionais e internacionais. Há na comunidade científica algo similar à luta de classes de Marx (FOUREZ, 1995). 


\section{Considerações finais}

Se num exercício de imaginação fosse possível transportar a diversidade dos personagens Marvel e as suas formas de ser para a realidade, eles estariam plenamente ajustados ao momento em que se encontra a perspectiva da ciência contemporânea. Supondo que a ciência seja o "bem" personificado nos heróis Marvel e o "mal" habite em seus "inimigos". A luta entre o "bem" e o "mal" dos filmes Marvel pode ser a metáfora da crise da ciência na qual, cientistas tentam defender suas posições adquiridas com um histórico de autoridade, eficiência e superioridade que estão sendo questionadas pelos que, ao mesmo tempo, apontam as fragilidades da condição da ciência e defendem aqueles que foram marginalizados, discriminados e até criminalizados por ela.

O Tony Stark da ficção é a representação de cientista vista como modelo por parte dos historiadores, filósofos e sociólogos da ciência que têm contribuído para amenizar o discurso que aponta as fragilidades e, por vezes invertem as queixas contra os próprios proponentes das mudanças necessárias, acreditando que a ciência causou mais mal que bem. Por este motivo, ela deve dar lugar ou assimilar outras formas de saber para equilibrar as consequências de séculos de domínio absoluto da ciência moderna.

Outro aspecto que confronta ficção e realidade, é a ideia de ciência tratada dogmaticamente como linguagem superior do homem, especificamente do gênero masculino, para dominar, manipular e subordinar a natureza. Esse predomínio humano ${ }^{37}$ e masculino, reforça um aspecto já mencionado no item anterior sobre a ciência, reproduzido na ficção que é a questão sexista: as figuras femininas dos episódios Marvel usados aqui como objeto de análise, são todas secundárias ou coadjuvantes.

37 THOMAS, Keith. O Homem e o Mundo Natural. $4^{a}$ reimpressão. Ed. Companhia das Letras, são Paulo, 2001.
Se há alguma possibilidade de estabelecer a correlação entre realidade e ficção com o exemplo proposto neste texto, considere-se que a reunião dos Vingadores para combater o "mal" que põe em risco a existência de forma geral, poderia representar ficcionalmente o que na proposição crítica da História da Ciência refere-se à necessidade de reorientação das ciências e dos cientistas à uma prática transdisciplinar para dar conta dos problemas da realidade complexa que, atualmente, tem gerado tanta instabilidade e incerteza nas expectativas humanas.

\section{Referências}

\section{BACHELARD, G. A Formação do Espírito Cientí-} fico. Rio de Janeiro: Ed. Contraponto, 1996. 316 p. BOFF, L. Saber Cuidar. 20. ed. Petrópolis: Ed. Vozes, 2014. 248 p.

BOHM, D. Totalidade e a Ordem Implicada. São Paulo: Madras Ed., 2008. 222 p.

BONDI, H. (Org.). O que é Progresso em Ciência? In: HARRÉ, Ron et al (Org.). Problemas da Revolução Científica: Incentivos e obstáculos ao progresso das ciências. Belo Horizonte/ São Paulo: Ed. Itatiaia/Edusp, 1976. Cap. 1. p. 17-26. (O homem é a ciência)

BRANCO, J.M. F. Dialéctica, Ciência e Natureza: um estudo sobre a noção de "dialéctica da natureza" no quadro do pensamento científico moderno. Lisboa: Ed. Caminho, 1989. 316 p.

BRENNAN, R. Gigantes da Física: Uma história da física moderna através de oito biografias. Rio de Janeiro: Zahar Ed., 2003. 292 p.

BURTT, E. A. As Bases Metafísicas da Ciência Moderna. Brasília: Ed. UNB, 1983. 268 p.

CAPRA, F. O Ponto de Mutação. São Paulo: Ed. Cultrix, 2006. 448 p.

CASINI, P. As Filosofias da Natureza. 2. ed. Lisboa: Ed. Presença, 1987. 144 p. 
CHALMERS, A. A Fabricação da Ciência. São Paulo: Ed. Unesp, 1994. 185 p.

CHASSOT, A. I. A Ciência é Masculina? É sim Senhora! São Leopoldo-RS: Ed. Unisinos, 2003. $136 \mathrm{p}$.

CHRETIEN, C. A Ciência em Ação. Campinas: Papirus Ed.; 1994. 268 p.

CONDÉ, M. L. L. Um Papel para a História: o problema da historicidade da ciência. Curitiba: Ed. UFPR, 2017. 171 p.

DAMPIER, W. C. História da Ciência. São Paulo: Ed. IBRASA, 1986. 239 p.

ENGELS, F. Anti-Duhring. A revolução da ciência segundo o sr. Eugen Duhring. São Paulo: Boitempo Ed., 2015. 380 p.

FEYERABEND, P. Contra o Método. São Paulo: Ed. Francisco Alves, 1989. 487 p.

FOUREZ, G. A Construção das Ciências: introdução à filosofia e à ética das ciências. São Paulo: Ed. Unesp, 1995. 319 p.

GRANGER, G-G. A Ciência e as Ciências. São Paulo: Ed. Unesp, 1994. 122 p.

HENRY, J. A Revolução Científica: e as origens da ciência moderna. Rio de Janeiro: Jorge Zahar Ed., 1998. 149 p.

JAPIASSU, H. O Mito da Neutralidade Científica. Rio de Janeiro: Imago Ed., 1975. 187 p.

KNELLER, G. F. A Ciência como Atividade Humana. Rio de Janeiro/São Paulo: Ed. Zahar/ Edusp, 1980. 310 p.

KUHN, T. A Estrutura das Revoluções Científicas. 3. ed. São Paulo: Ed. Perspectiva, 1994. 257 p.

MASON, S. História da Ciência: as principais correntes do pensamento científico. Rio de Janeiro/Porto Alegre/São Paulo: Ed. Globo, 1962. $527 \mathrm{p}$.

MERTON, R. K. Ensaios de Sociologia da Ciência. São Paulo: Ed. 34, 2013. 304 p.
MONOD, J.L. (Org.) A propósito da Teoria Molecular da Evolução. In: HARRÉ, Ron et al (Org.). Problemas da Revolução Científica: Incentivos e obstáculos ao progresso das ciências. Belo Horizonte/ São Paulo: Ed. Itatiaia/ Edusp, 1976. Cap. 1. p. 27-40. (O homem é a ciência)

MORIN, E. Introdução ao Pensamento Complexo. 5. ed. Porto Alegre: Ed. Sulina, 2015. 120 p. NISBET, R. História da Ideia de Progresso. Brasília: Ed. UNB, 1985. 363 p.

POPPER, K. R. A Lógica da Pesquisa Científica. 2. ed. São Paulo: Ed. Cultrix, 2013. 454 p.

PRIGOGINE E STENGERS, Ilya e STENGERS, Isabelle. A Nova Aliança: metamorfose da ciência. Brasília: Ed. UNB, 1984. 248 p.

RORTY, R. A Filosofia e o Espelho da Natureza. Rio de Janeiro: Ed. Relume-Dumará, 1994. 386 p. ROSSI, P. A Ciência e a Filosofia dos Modernos: aspectos da revolução científica. São Pulo: Ed. Unesp, 1992. 389 p.

SANTOS, B. S. Um Discurso sobre as Ciências. 5. ed. São Paulo: Cortez Ed., 2008. 92 p.

SCHWARTZMAN, S. A Ciência da Ciência. Ciência Hoje - SBPC. Rio de Janeiro, v. 2, n. 11, p.54-59, 1984. Março-abril.

SHAPIN, S. A Revolução Científica. Miraflores, Portugal: Difusão Ed., 1999. 230 p.

SHAPIN, S. Nunca Pura: estudos históricos de ciência como se fora produzida por pessoas com corpos, situadas no tempo, no espaço, na cultura e na sociedade e que se empenham por credibilidade e autoridade. Belo Horizonte: Ed. Fino Traço: 2013.546 p.

STENGERS, I. Os Casos Galileu. In: SERRES, Michel (Org.). Elementos para uma História das Ciências II: Do fim da idade média a Lavoisier. Lisboa: Terramar, 1989. Cap. 2. p. 37-68. 
SZAMOSI, G. Tempo \& Espaço: as dimensões gêmeas. Rio de Janeiro: Jorge Zahar Ed., 1988. $277 \mathrm{p}$.

THOMAS, K. O Homem e o Mundo Natural. São Paulo: Ed. Companhia das Letras, 1988. $454 \mathrm{p}$.
WITTGENSTEIN, L. Tractatus Logico-

Philosophicus. 3. ed. São Paulo: Edusp, 1968.152 p. ZANETIC, João. A Propósito do artigo de B. Hessen sobre o "Principia" de Newton. URL http://www.sbfisica.org.br/rbef/pdf/vol06a05. pdf acesso 30.07.2019 